
\title{
25 Research Soure \\ What Really Matters for Returning to Work After Breast Cancer? A 6-month Longitudinal Study and a Multidimensional Approach
}

\section{Elena Fiabane}

Istituti Clinici Scientifici Maugeri SpA ICS Genova Nervi

Paola Dordoni ( $\triangle$ paola.dordoni@icsmaugeri.it )

Istituti Clinici Scientifici Maugeri SpA IRCCS Pavia https://orcid.org/0000-0002-1984-2502

Cecilia Perrone

Istituti Clinici Scientifici Maugeri SpA IRCCS Pavia

Antonio Bernardo

Istituti Clinici Scientifici Maugeri SpA IRCCS Pavia

\section{Fabio Corsi}

Istituti Clinici Scientifici Maugeri SpA IRCCS Pavia

Paola Gabanelli

Istituti Clinici Scientifici Maugeri SpA IRCCS Pavia

\section{Research Article}

Keywords: return to work, breast cancer, chemiotherapy, expectations

Posted Date: January 14th, 2022

DOI: https://doi.org/10.21203/rs.3.rs-1174844/v1

License: () (1) This work is licensed under a Creative Commons Attribution 4.0 International License.

Read Full License 


\section{Abstract \\ Purpose.}

Return to work (RTW) after breast cancer (BC) may easily impact on women recovery and quality of life. Literature on RTW hightlighed several factors associated to RTW after BC, and there is still some concern for exploring the main sociodemographic, clinical, psychological and work-related predictors of RTW after $\mathrm{BC}$ treatments especially when considering the first 6 months. The present study aims to explore which baseline factors are associated with RTW at 6-month after BC surgery.

\section{Methods.}

A 6-month follow-up study was performed among patients recruited from a Hospital in Northern Italy after their cancer-related surgery. Partecipants filled in a battery of questionnaires at baseline and at 6month follow-up. Measurements were on job stress, work engagement, quality of life, anxiety, depression and resilience. Moreover, sociodemographic, clinical and work-related data were collected. Univariate and multivariate analyses were performed.

\section{Results.}

We recruited a sample of 149 patients, whose $73.9 \%$ returned to work after surgery. The women who returned to work were more likely to be not in a relationship, nor to have children. Also, they were not treated by chemiotherapy, and had higher scores in expectations of job changes after illness, RTW expectations, perception of physical quality of life and psychological resilience. In the multivariate model, chemiotherapy and women's RTW expectations resulted as significant predictors of RTW at 6-month after $\mathrm{BC}$ surgery.

\section{Conclusion}

Most patients returned to work within first 6 months from breast surgery. Return to work was influenced by chemiotherapy and RTW expectations at baseline. A carefully individual screening of risk factors at baseline can prevent from occupational disability and long sickness absence.

\section{Introduction}

Early diagnosis and improvements in treatment in most developed countries have increased in the number of breast cancer (BC) survivors [1] which means that more cancer survivors might be capable of returning to work (RTW). BC is the most widespread cancer in women, which frequently requires a combination of treatment modalities that can be associated with longer treatment and recovery time $[2,3]$. 
Among female cancer in Italy, BC is the most frequent with 54.976 new diagnoses in 2020, representing $30.3 \%$ among all female cancers (www.aiom.it). BC occurs most frequently in middle-aged women that are in a life stage vital for business development and work in addition to family management. For most women, diagnosis of $\mathrm{BC}$ implies a change in working conditions such as a temporary interruption or work limitations due to the disease or treatments and their side effects, while some other patients never return to work (RTW) $[4,5]$. The RTW represents a relevant event for cancer patients since it is a symbol of complete recovery and regain of the normal life [6,7]; in addition, several studies showed that it also facilitates an increasing in quality of life and mental health [6,8-10].

Literature on RTW after BC may be seen as a process made up of stages involving several aspects, such as clinical, socio-demographic, psychological and work-related factors [11].

Overall, chemotherapy is widely associated with prolonged period of sick leave [12-14]. Regarding the treatments, mastectomy and axillary node dissection, irradiation to breast or chest wall, hormone and radiotherapy were also found to be important barriers to RTW $[13,15]$. Early stage $B C$, fatigue and physical exhaustion were found to hinder women's RTW $[16,17]$.

Among socio-demographic factors, BC survivors with higher education, younger age and not in a relationship were more likely to RTW compared to others $[13,15,17]$. Furthermore, there are several psychological factors, which may influence patients' decision to RTW, such as life satisfaction, selfmotivation, emotional distress, fatigue, social support, depression and anxiety [13,15]. Previous studies found that work-related factors, such as having a manual job, heavy job demands, high levels of occupational stress, lack of supervisor or coworkers support resulted as barriers of RTW $[8,13,18]$. Also, $\mathrm{BC}$ women who RTW mostly look forward to a flexible working schedule, non-manual job and job security [13].

BC women pass through the status of patient to the status of survivor wishing to resume a "normal life". The first period is crucial for women to recover and regain psychological resources. Indeed, the first 6month period after treatment is a time window called "in-between" because of its important impact on RTW [11]. An in-depth analysis of this delicate time window could provide a better comprehension of this stage and support clinicians interventions for RTW.

In addition, previous studies showed that early interventions are the key for preventing disability since the longer a worker is absent from work due to illness, the less likely that person is to return to work [19].

Reintegration into the workplace after illness is strongly recommended since it is associated with improved quality of life and mental health status [8]. Given the multidimensional nature of RTW, it is important to explore prospectively which factors may promote or impede work reintegration in the specific context of BC.

Therefore, the aim of this study was to explore which baseline sociodemographic, clinical, psychological and work-related factors predict RTW at 6-month after breast cancer surgery. 


\section{Materials And Methods}

The participants in this 6-month prospective study were 181 patients who underwent breast cancerrelated surgery and accessed our Oncology Clinic for cancer therapy from March 2017 to December 2019 in North Italy. Participants fulfilled the following inclusion criteria: a) diagnosis of first primary invasive breast cancer (all stages); b) recently having completed surgical intervention; c) being employed at the time of diagnosis; $d$ ) ageing between 18 and 60 years at the diagnosis time. We excluded individuals with: a) prior history of cancer other than non-melanoma skin cancer; b) presence of cerebral metastasis; c) unemployment in the six months before the diagnosis.

The data were collected at baseline during the hospitalization (mean $=1.43( \pm 2.43)$ days after surgery) and at 6-months follow-up when patients were evaluated by means of phone interview. At baseline, participants completed questionnaires regarding socio-demographic, psychological and work-related factors. We collected information about patients' definitive return to work or not at 6-month follow-up assessment.

Thirty-two patients out of $181(17.7 \%)$ refused to participate, resulting in a final sample of 149 patients eligible for this study (82.3\%).

The study was approved by the local Independent Ethics Committee at "IRCCS Istituti Clinici Scientifici Fondazione Maugeri” (Number Protocol: 2136). Written informed consent was obtained from all participants.

\section{Materials}

Job Content Questionnaire (JCQ). Job stress was investigated using scales from the Job Content Questionnaire (JCQ) [20]. The original version consists of 49 items scored from 1 (completely disagree) to 4 (completely agree). The components measured for this study were: skill discretion (6 items), decision authority (4 items), psychological job demands ( 9 items), physical job demands ( 2 items), supervisor support (4 items), coworker support (4 items).

Utrecht Work Engagement Scale (UWES-9) [21]. Work engagement was measured with the Utrecht Work Engagement Scale (10 item) which included the following three subscales: vigor (3 items), dedication (3 items), and absorption ( 3 items). Responses to items were given on a frequency scale varying from 0 (never) to 6 (always). The higher the score, the greater the work engagement.

The World Health Organization Quality of Life-BREF (WHOQOL-BREF). In order to investigate the perception of Quality of Life (QoL), the World Health Organization Quality of Life was used (26 item) [22]. It is the short form of the WHOQOL-100 [23] and assesses 24 domains of general QoL grouped in four domains: physical health ( 7 items), psychological health (6 items), social relationships (3 items), and environment (8 items). Additionally, 2 items about overall QoL and general health were considered. Scores range from 1 to 5 and are recoded into 1-100 scores. The higher the scores, the greater the quality of life. 
Hospital Anxiety and Depression Scale (HADS). Anxiety and depression symptoms were investigated by the Hospital Anxiety and Depression Scale [24]. It is a 14-item scale composed by two subscales: anxiety (7 items) and depression (7 items). The lowest possible scores for depression and anxiety are 0 , and the highest possible scores are 21 . Higher scores indicate great severity of anxiety or depression.

Connor-Davidson Resilience Scale (CD-RISC). The short form of the CD-RISC scale [25] was used to investigate resilience. Items were rated on a 5-item scale ranging from 1 (strongly disagree) to 5 (strongly agree). The resilience score was calculated as the average of the items; higher scores indicate greater resilience.

RTW expectancy. A single item was used to evaluate baseline patient's expectations for RTW after BC surgery ("Do you expect to return to work?"), using a 1-10 slider scale, higher scores meaning higher RTW expectancy.

Expectancy of job changes after illness. A single item was used to evaluate baseline patient's expectations of job changes when they will return to work ("Do you expect to change your job/position after illness?") using a dichotomous scale (Yes/No).

\section{Statistical Analyses}

All analyses were performesd using SPSS for Windows version 19.0. Preliminary analyses were conducted in order to test the causality of the hypothesized model. Women who did and did not return to work within T1 were compared on socio-demographic, medical and psychological variables using independent $\mathrm{t}$-test for continuous variables and Chi-square test for categorical variables. Only variables with significant results $(\mathrm{p}<.05)$ with return to work were used in the model. Logistic regression model was then used to test our research hypothesis. The model was adjusted for socio-demographic (age) and job variables (professional category, type of job). We included these covariates because many previous studies found them to be related significantly to RTW and sickness absence $[8,26]$.

\section{Results}

\section{Total Sample}

Baseline characteristics of the sample are presented in Table 1. The mean age was 50.30 (DS=6.16), the majority of women was in a relationship (75\%) and referred having children (79.1\%). Partecipants had a mean education of 13.74 years, and $54.9 \%$ reported their husband as the caregiver. As regards with medical characteristics, $69.2 \%$ of women did not receive chemotherapy (only or combined), $86.5 \%$ did not receive radiotherapy (only) and $80.5 \%$ did not receive hormonetherapy (only). $76.9 \%$ of partecipants did not have axillary dissection while $63.4 \%$ had a sector resection. $70.7 \%$ of the sample had no previous diseases. Concerning their job, the majority of participants worked full-time (75.0\%) and was employed $(87.3 \%)$ as white-collar (69.4\%). Furthermore, the mean of seniority with the current job was 18.92 (yrs) $(S D=10.19)$, while the mean of the total seniority was 26.85 (yrs) $(S D=8.66)$. As showed in Table 2, at 
baseline $88.6 \%$ of women believed that no job changes will be necessary when returning to work. Additionaly, a high score of RTW expectation was found ( $M=9.26$; $D S=1.58$; range 1-10)

\section{Differences between RTW and NOT RTW groups}

$73.9 \%$ of the total sample returned to work at 6 -month follow-up. Women who did and did not return to work within 6-month were compared on socio-demographic, clinical and psychological variables (Table 1 and 2). Results evidenced that RTW patients were less likely to be in a relationship $\left(X^{2}=4.45 ; p=0.035\right)$, they tended to have less children $\left(X^{2}=4.35 ; p=0.37\right)$ and they were less likely to receive chemiotherapy (only or combined) $\left(X^{2}=7.014 ; p=0.011\right)$ compared to the NOT RTW group. Moreover, the RTW group frequently had less expectancies of job changes after illness $\left(X^{2}=6.25 ; p=0.012\right)$, and scored higher in RTW expectancy $(Z=-2.070 ; p=0.038)$, physical quality of life $(Z=-2.093 ; p=0.036)$ and resilience $(Z=$ $-2.120 ; p=0.034)$ compared to the other group.

\section{Baseline predictor of RTW at T1}

Logistic regression analyses were used in order to study the predictor of RTW after 6 months. As showed in Table 3, receiving chemiotherapy $(B=-1.428 ; S E=0.520)$ and women' RTW expectancy $(B=-0.340 ; D S=$ 0.156) predicted patients' RTW at T1.

\section{Discussion}

RTW after BC is a relevant topic considering the increase of breast cancer incidence, the age of the diagnosis and the decrease of mortality due to news diagnostic and therapeutic tools. RTW literature underlined the multifactorial nature of RTW process and need of timely interventions since the duration of sickness absence is negatively associated with the probability of RTW. Therefore, this study aimed to focus on the first 6-month after breast surgery to explore relevant predictors of RTW, from a multidimensional perspective.

In this study we found a rate of RTW 6-month after surgery (73.9\%) in line with the [13] showing that even few months after surgery most women decided to RTW. Among the socio-demographic factors, we found that RTW was associated with being not married and not having children. Previous findings suggested that women without a partner and children are more likely to RTW $[13,16]$. It is plausible that financial insecurity or investment in career may be the reasons $[27,28]$. In addition, single women may be more likely to perceive a sense of loneliness when coming back home after surgery, hence conceiving RTW as regaining the own normal life $[6,7]$.

Surprisingly, in our study, age and type of job were not significant factors influencing RTW. Based on the literature, we expected that youger women with a white collar position were more likely to RTW after surgery [13] but it is plausible that the high percentage of white collar women in our sample has impacted on this result. 
As regards with clinical factors, our findings confirmed that chemotherapy is a relevant risk factor for not returning to work $[18,29,30]$ while other treatments or clinical factors did not have a significant effect. In line with this, our findings suggested that the baseline perception of physical QoL predicted RTW at follow-up. This means that women who perceived physically healthy are more oriented to RTW after surgery, so that personal evaluations and beliefs on self-efficacy may influence women's behaviors and decisions.

One of the main results of our study is the strong impact of personal expectations on RTW. The great RTW expectancy at baseline resulted to be a relevant predictor of RTW at 6-month after surgery. Patient expectations have been demonstrated previously to relate to a variety of recovery indicators including surgical outcomes, treatment adherence and disability duration [31].

Overall, our study suggested that marital-status single women without children, with possible high investment in their job and with positive perception of physical quality of life are more likely to RTW 6months after surgery. Moreover, when motivated and positively hopeful, women RTW 6-months after surgery. We may assume that job may help these women to perceive a good self-image and psychological identity. RTW can be considered a protecting factor for psychological health after cancer treatment. Taken all together these results suggest that when women have positive expectancy and feel motivation to RTW as well as self-efficacy on the job, they may feel stronger and much more available to deal with work demands even after cancer. This concept may be related to the psychological resilience, which resulted as a distinctive characteristic of RTW women in our study. In conclusion, the present research highlighted the key role of women expectation about RTW and individual evaluation of physical health, that means self-confidence and perception of self-efficacy on the job. When you believe you can do it, you are halfway there.

\section{Study limitations}

Some limitations should be acknowledged. First, all measurements used were self-reported, a commonmethod bias may exist [32]. Second, our sample consisted of patients enrolled in a single hospital, therefore generalizability of our findings might be limited.

Third, we are aware that our sample is characterized by a higher percentage of white collar women employed in an organization. In future studies, both type of job and work status should be taken into account in multi-group analyses.

\section{Clinical implications}

Our findings have important practical implications for healthcare organizations and for clinicians working with $\mathrm{BC}$ women. Our results recommend a baseline psychological screening for these women: even if common evaluation (such as anxiety and depression) might result appropriate, it could be useful to explore RTW expectations since they can be barriers to the complex process of work reintegration after illness. Indeed, when there are positive expectancy on RTW at baseline, it may be possible that women are 
more likely to RTW 6-month after surgery. As a matter of fact, the psychologist can help clinicians evaluating and monitoring the course of these expectations during the path. $\mathrm{BC}$ women who are hesitant in RTW may benefit from psychological support, specifically on reinforcing self-image as a workable woman when dealing with rehabilitation. Lastly, patients treated with chemotherapy should be monitored carefully since they are at high risk for not returning to work. Therefore, timely interventions such as work accomodations based on patients' needs could be a useful strategy to prevent work disability.

\section{Declarations}

\section{Compliance with Ethical Standards:}

Conflicts of interest: the authors declare that they have no conflict of interest.

Informed consenses: informed consent to partecipate in the study has been obtained from all partecipants

Consent to publication: all partecipants consent to publish their data to a journal

Funding: no found.

Conflicts of interest/Competing interests: the authors declare that they have no conflict of interest.

Availability of data and material: requests to access the datasets should be directed to the corresponding author.

Code availability: not applicable

Authors' contributions:

Conceptualization: EMF, PG; Methodology: EMF, PD, PG; Formal analysis and investigation: EMP, PD; Writing - original draft preparation: EMF, PD; Writing - review and editing: EMF, PD, AB, FC, PG; Supervision: PG.

Ethics approval: the study has been approved by the Ethics Commitee at Fondazione Maugeri (Number Protocol: 2136)

Consent to participate: Informed consent was obtained from all individual participants included in the study.

Consent for publication: all participants consented to publish their data to a journal

\section{References}


1. Carioli G, Malvezzi M, Rodriguez T, Bertuccio P, Negri E, La Vecchia C (2017) Trends and predictions to 2020 in breast cancer mortality in Europe. The Breast 36:89-95.

2. De Boer AG, Verbeek JH, Spelten ER, Uitterhoeve AL, Ansink AC,de Reijke TM, Kammeijer M, Sprangers MA, van Dijk FJ (2008) Work ability and return-to-work in cancer patients. Br J Cancer 98(8):1342-1347. https://doi.org/10.1038/sj.bjc.6604302

3. Gudbergsson SB, Torp S, Fløtten T, Fosså SD, Nielsen R, Dahl AA (2011) A comparative study of cancer patients with short and long sick-leave after primary treatment. Acta Oncol 50(3):381-389. https://doi.org/10.3109/0284186X.2010.500298

4. Damkjaer LH, Deltour I, Suppli NP, Christensen J, Kroman NT, Johansen C, Dalton SO (2011) Breast cancer and early retirement: associations with disease characteristics, treatment, comorbidity, social position and participation in a six-day rehabilitation course in a register-based study in Denmark. Acta Oncol 50(2):274-281. https://doi.org/10.3109/0284186X.2010.531048

5. Tiedtke C, de Rijk A, Dierckx de Casterle B, Christiaens MR, Donceel P (2010) Experiences and concerns about 'returning to work' for women breast cancer survivors: a literature review.

Psychooncology 19(7):677-683. https://doi.org/10.1002/pon.1633

6. Spelten ER, Sprangers MAG, Verbeek JH (2002) Factors reported to influence the return to work of cancer survivors: a literature review. Psychooncology 11:124-131.

7. Kennedy F, Haslam C, Munir F, Pryce J (2007) Returning to work following cancer: a qualitative exploratory study into the experience of returning to work following cancer. Eur $\mathrm{J}$ Cancer Care 16:1725

8. Sohn KJ, Sun-Young P, Sue K (2021) A scoping review of return to work decision-making and experiences of breast cancer survivors in Korea. Supportive Care in Cancer 29:1741-1751

9. Schmidt ME, Scherer S, Wiskemann J \& Steindorf K (2019) Return to work after breast cancer: The role of treatment-related side effects and potential impact on quality of life. European journal of cancer care 28(4): 13051.

10. Sanchez KM, Richardson JL \& Mason HR (2004). The return to work experiences of colorectal cancer survivors. AAOHN journal 52(12): 500-510.

11. Bilodeau K, Tremblay D, \& Durand MJ (2019). Return to work after breast cancer treatments: Rebuilding everything despite feeling "in-between". Eur J of Oncology Nursing 41:65-172.

12. Hedayati E, Johnsson A, Alinaghizadeh H, Schedin A, Nyman H, Albertsson M (2013) Cognitive, psychosocial, somatic and treatment factors predicting return to work after breast cancer treatment. Scandinavian journal of caring sciences 27(2):380-387.

13. Islam T, Dahlui M, Abd Majid H, Nahar AM, Taib NAM, Su TT (2014) Factors associated with return to work of breast cancer survivors: a systematic review. BMC public health 14(3):1-13.

14. Paltrinieri S, Vicentini M, Mazzini E, Ricchi E, Fugazzaro S, Mancuso P, Rossi PG, Costi S (2019) Factors influencing return to work of cancer survivors: a population-based study in Italy. Support Care Cancer 28: 701-712 . https://doi.org/10.1007/s00520-019-04868-0 
15. Colombino ICF, Sarri AJ, Queiros Castro I, Paiva1 CE, Aloisio da Costa Vieira R (2020) Factors associated with return to work in breast cancer survivors treated at the Public Cancer Hospital in Brazil. Supportive Care in Cancer 28:4445-4458. https://doi.org/10.1007/s00520-019-05164-7

16. Johnsson A, Fornander T, Olsson M, Nystedt M, Johansson H \& Erik Rutqvist L (2007). Factors associated with return to work after breast cancer treatment. Acta Oncologica 46(1): 90-96.

17. Carlsen K, Jensen AJ, Rugulies R, Christensen J, Bidstrup PE, Johansen C, Huitfeldt Madsen IE, Dalton SO (2013) Self-reported work ability in long-term breast cancer survivors. A population-based questionnaire study in Denmark. Acta Oncologica 52(2):423-429. https://doi.org/10.3109/0284186X.2012.744877

18. Fantoni SQ, Peugniez C, Duhamel A, Skrzypczak J, Frimat P, Leroyer A (2010) Factors related to return to work by women with breast cancer in northern France. J Occup Rehabil 20(1): 49-58. https://doi.org/10.1007/s10926-009-9215-y.

19. Fiabane E, Argentero P, Calsamiglia G et al. (2013) Does job satisfaction predict early return to work after coronary angioplasty or cardiac surgery?. Int Arch Occup Environ Health 86: 561569. https://doi.org/10.1007/s00420-012-0787-z

20. Baldasseroni A, Camerino D, Cenni P, Cesana GC, Fattorini E, Ferrario M, Mariani M, Tartaglia R (2001) La valutazione dei fattori psicosociali. Proposta della versione italiana del Job Content Questionnaire di R.A. Karasek. ISPSEL.

21. Balducci C, Fraccaroli F, Schaufeli WB (2010) Psychometric Properties of the Italian Version of the Utrecht Work Engagement Scale (UWES-9). A Cross-Cultural Analysis. European Journal of Psychological Assessment 26:143-149.

22. De Girolamo G, Rucci P, Scocco P, Becchi A, Coppa F, D’Addario A, Darù E, De Leo D, Galassi L, Mangelli L, Marson C, Neri G, Soldani L (2000) La valutazione della qualità di vita: validazione del WHOQOL- BREVE. http://www.lindasoldani.it/articoli/whoqol.pdf

23. Skevington SM., Lotfy M, O'Connell KA (2004) The World Health Organization's WHOQOL-BREF quality of life assessment: Psychometric properties and results of the international field trial. A report from the WHOQOL group. Qual. Life Res. 13:299-310

24. Zigmond AS, Snaith RP (1983) The Hospital Anxiety And Depression Scale. Acta Psychiatrica Scandinavica 67:361-370

25. Campbell-Sills L, Stein MB (2007). Psychometric Analysis and Refinement of the Connor-Davidson Resilience Scale (CD-RISC): Validation of a 10-Item Measure of Resilience. Journal of Traumatic Stress 20(6):1019-1028.

26. Van Muijen P, Weevers NLEC, Snels IA, Duijts SFA, Bruinvels DJ, Schellart AJ \& Van Der Beek AJ (2013). Predictors of return to work and employment in cancer survivors: a systematic review. European journal of cancer care 22(2): 144-160.

27. Tamminga SJ, De Boer AG, Verbeek JH \& Frings-Dresen MH (2012). Breast cancer survivors' views of factors that influence the return-to-work process-a qualitative study. Scandinavian journal of work, environment \& health 144-154. 
28. Drolet, M., Maunsell, E., Mondor, M., Brisson, C., Brisson, J., Mâsse, B., \& Deschênes, L. (2005). Work absence after breast cancer diagnosis: a population-based study. Cmaj 173(7): 765-771.

29. Lilliehorn S, Hamberg K, Kero A \& Salander P (2013). Meaning of work and the returning process after breast cancer: a longitudinal study of 56 women. Scandinavian journal of caring sciences 27(2):267-274.

30. Dumas A, Luis IV, Bovagnet T, El Mouhebb M, Di Meglio A, Pinto S \& Menvielle G (2020). Impact of breast cancer treatment on employment: results of a multicenter prospective cohort study (CANTO). Journal of Clinical Oncology 38(7):734

31. Cancelliere C, Donovan J, Stochkendahl MJ et al (2016). Factors affecting return to work after injury or illness: best evidence synthesis of systematic reviews. Chiropr Man Therap 24-32. https://doi.org/10.1186/s12998-016-0113

32. Podsakoff PM, Mackenzie SB, Lee JY and Podsakoff NP (2003). Common method biases in behavioral research: a critical review of the literature and recommended remedies. J. Appl. Psychol. 88:879. https://doi.org/10.1037/0021-9010.88.5.879

\section{Tables}

Table 1. Baseline sociodemographic, work-related and clinical characteristics of the total sample and differences between RTW groups $(\mathrm{N}=149)$ 


\begin{tabular}{|c|c|c|c|c|c|}
\hline & TOTAL & $R T W$ & NOT RTW & $x^{2}$ & $p$ \\
\hline & $\%(N)$ & $\%(N)$ & $\%(N)$ & & \\
\hline In a relationship & & & & 4.45 & 0.035 \\
\hline Yes & 75.0(101) & $69.3(70)$ & $30.7(31)$ & & \\
\hline No & $24.0(33)$ & $87.9(29)$ & $12.1(4)$ & & \\
\hline Children & & & & 4.35 & 0.037 \\
\hline Yes & 79.1(106) & $69.8(74)$ & $30.2(32)$ & & \\
\hline No & $20.9(28)$ & $89.3(25)$ & $10.7(3)$ & & \\
\hline Caregiver & & & & 3.15 & 0.368 \\
\hline Husband & $54.9(73)$ & $68.5(50)$ & $31.5(23)$ & & \\
\hline Husband and son & $12.0(16)$ & $75(12)$ & $25.0(4)$ & & \\
\hline Mother, brother/sister & $8.3(11)$ & 72.7(8) & $27.3(3)$ & & \\
\hline Other & 24.8(33) & $84.8(28)$ & $15.2(5)$ & & \\
\hline Chemiotherapy $^{1}$ & & & & 7.01 & 0.011 \\
\hline Yes & $30.8(41)$ & $58.5(24)$ & $41.5(17)$ & & \\
\hline No & $69.2(92)$ & $80.4(74)$ & 19.6(18) & & \\
\hline Radiotherapy² & & & & 0.32 & 0.399 \\
\hline Yes & 13.5(18) & $83.3(15)$ & $16.7(3)$ & & \\
\hline No & $86.5(115)$ & $72.2(83)$ & $27.8(32)$ & & \\
\hline Hormonetherapy ${ }^{3}$ & & & & 0.94 & 1.000 \\
\hline Yes & 19.5(26) & 73.1(19) & $26.9(7)$ & & \\
\hline No & $80.5(107)$ & 73.8(79) & $26.2(28)$ & & \\
\hline Axillary dissection & & & & 0.18 & 0.649 \\
\hline Yes & 23.1(31) & $71.0(22)$ & $29.0(9)$ & & \\
\hline No & $76.9(103)$ & $74.8(77)$ & $25.2(26)$ & & \\
\hline Previous diseases & & & & 0.30 & 0.669 \\
\hline Yes & 29.3(39) & $76.9(30)$ & 23.1(9) & & \\
\hline No & 70.7(94) & $72.3(68)$ & $27.7(26)$ & & \\
\hline Cancer-related surgery & & & & 0.93 & 0.545 \\
\hline
\end{tabular}




\begin{tabular}{|llllll|}
\hline Sector resection & $63.43(85)$ & $74.11(63)$ & $25.88(22)$ & & \\
Mastectomy & $36.56(49)$ & $73.46(36)$ & $26.53(13)$ & & \\
Work status & & & & 0.39 & 0.823 \\
Full time & $75(99)$ & $74.7(74)$ & $25.3(25)$ & & \\
Part time & $22(29)$ & $69.0(20)$ & $31.0(9)$ & & \\
Other & $3(4)$ & $75.0(3)$ & $25.0(1)$ & & \\
\hline Professional category & & & & -1.82 & 0.068 \\
\hline Blue collar & $30.59(41)$ & $63.41(26)$ & $36.58(15)$ & & \\
\hline White collar & $69.40(93)$ & $78.49(73)$ & $21.50(20)$ & & \\
\hline Type of Job & & & & 2.08 & 0.237 \\
Employed & $87.3(117)$ & $71.8(84)$ & $28.2(33)$ & & \\
Self-employed & $12.7(17)$ & $88.2(15)$ & $11.8(2)$ & & \\
\hline & TOTAL & $R T W$ & $N O T R T W$ & $Z$ & $p$ \\
\hline Age & $M(S D)$ & $M(S D)$ & $M(S D)$ & & \\
\hline Education (yrs) & $50.30(6.16)$ & $50.24(5.84)$ & $50.45(6.98)$ & -0.33 & 0.738 \\
\hline Seniority with actual job (yrs) & $18.92(10.19)$ & $19.83(9.60)$ & $16.26(12.07)$ & -1.75 & 0.080 \\
\hline Seniority total (yrs) & $26.85(8.66)$ & $27.57(7.89)$ & $25.61(10.70)$ & -0.76 & 0.449 \\
\hline
\end{tabular}

${ }^{1}$ Yes = only chemiotherapy or combined; No = no chemiotherapy;

${ }^{2}$ Yes = only radiotherapy; No = no radiotherapy;

${ }^{3}$ Yes = only hormonetherapy; No = no hormonetherapy;

Table 2. Differences at baseline in psychological factors between RTW and not-RTW groups $(\mathrm{N}=149)$ 


\begin{tabular}{|c|c|c|c|c|c|}
\hline & $\begin{array}{l}\text { TOTAL } \\
\%(N)\end{array}$ & $\begin{array}{l}R T W \\
\%(N)\end{array}$ & $\begin{array}{l}\text { NOT RTW } \\
\%(N)\end{array}$ & $x^{2}$ & $p$ \\
\hline \multirow[t]{2}{*}{$\begin{array}{l}\text { Expectancy of job changes after } \\
\text { RTW }\end{array}$} & $\begin{array}{l}11.4(15) \\
88.6(117)\end{array}$ & $\begin{array}{l}46.7(7) \\
76.9(90)\end{array}$ & $\begin{array}{l}53.3(8) \\
23.1(27)\end{array}$ & 6.25 & 0.012 \\
\hline & $\begin{array}{l}\text { TOTAL } \\
M(S D)\end{array}$ & $\begin{array}{l}R T W \\
M(S D)\end{array}$ & $\begin{array}{l}\text { NOT RTW } \\
M(S D)\end{array}$ & $z$ & $p$ \\
\hline RTW expectancy & $9.26(1.58)$ & $9.47(1.34)$ & $8.68(2.16)$ & -2.07 & 0.038 \\
\hline \multicolumn{6}{|l|}{ Job stress } \\
\hline Skill discretion & $33.36(5.00)$ & $33.47(4.67)$ & $33.45(5.10)$ & -0.18 & 0.854 \\
\hline Decision authority & $33.40(6.67)$ & 33.14(7.03) & $33.87(6.92)$ & -0.81 & 0.417 \\
\hline Psychological Job demand & 23.03(3.96) & 23.39(4.29) & $22.42(3.14)$ & -1.01 & 0.312 \\
\hline \multicolumn{6}{|l|}{ Physical Job demand } \\
\hline Supervisor support & $6.29(1.97)$ & $6.47(1.94)$ & $5.96(1.97)$ & -1.38 & 0.168 \\
\hline \multirow[t]{2}{*}{ Coworker support } & 11.01(3.59) & $11.36(4.12)$ & 10.68(1.83) & -0.79 & 0.426 \\
\hline & $11.70(1.85)$ & $11.87(1.89)$ & $11.57(1.25)$ & -1.01 & 0.313 \\
\hline \multicolumn{6}{|l|}{ Work engagement } \\
\hline Vigor & $4.23(1.40)$ & $4.28(1.32)$ & $4.30(1.48)$ & -0.33 & 0.744 \\
\hline Dedication & $4.41(1.30)$ & $4.51(1.15)$ & $4.32(1.50)$ & -0.23 & 0.816 \\
\hline Absorption & $4.58(1.25)$ & $4.67(1.14)$ & $4.60(1.30)$ & -0.05 & 0.962 \\
\hline Quality of life & $64.54(14.72)$ & $66.57(15.03)$ & 60.84(13.08) & -2.09 & 0.036 \\
\hline Physical & 61.52(12.53) & $62.56(12.46)$ & $59.27(12.83)$ & -0.97 & 0.330 \\
\hline Psychological & 72.38(12.34) & 73.39(12.57) & 71.92(11.17) & -0.67 & 0.502 \\
\hline Social & $59.95(11.29)$ & 61.67(10.61) & $57.85(12.52)$ & -1.30 & 0.193 \\
\hline \multicolumn{6}{|l|}{ Environment } \\
\hline Anxiety & $9.69(4.58)$ & $9.70(4.47)$ & $9.30(4.79)$ & -0.55 & 0.579 \\
\hline Depression & $5.69(3.70)$ & $6.00(3.63)$ & $5.08(3.58)$ & -1.34 & 0.180 \\
\hline Resilience & $29.41(6.86)$ & $30.30(6.90)$ & 27.91(6.87) & -2.12 & 0.034 \\
\hline
\end{tabular}


Table 3. Baseline predictors of return to work at 6 months follow up $(\mathrm{N}=149)$

\begin{tabular}{|c|c|c|c|}
\hline & OR & $95 \% \mathrm{Cl}$ & $p$ \\
\hline In a relationship & 2.35 & $0.85-1.35$ & 0.125 \\
\hline Children & 1.02 & $0.11-2.04$ & 0.312 \\
\hline Chemiotherapy & 7.54 & $0.09-0.67$ & 0.006 \\
\hline Belief about job changes after RTW & 2.34 & $0.10-1.35$ & 0.126 \\
\hline RTW Expectacion ${ }^{a}$ & 4.77 & $0.52-0.97$ & 0.029 \\
\hline Physical QoL ${ }^{a}$ & 1.99 & $0.94-1.00$ & 0.158 \\
\hline Resilience $^{a}$ & 0.32 & 0.91-1.05 & 0.571 \\
\hline Nagelkerke $\mathrm{R}^{2}$ & 0.34 & & \\
\hline
\end{tabular}

This model is adjusted for socio-demographic(age) and job variables (professional category, type of job) ${ }^{\mathrm{a} O R}$ for one point increase 